15

\title{
Линзовый корректор волнового фронта для изучения плоских поверхностей
}

\author{
() М.Н. Торопов, А.А. Ахсахалян, И.В. Малышев, М.С. Михайленко, А.Е. Пестов, Н.Н. Салащенко, \\ А.К. Чернышов, Н.И. Чхало
}

Институт оризики микроструктур РАН, 607680 Нижний Новгород, Россия

e-mail: toropov@ipm.sci-nnov.ru, chkhalo@ipm.sci-nnov.ru

Поступило в Редакцию 14 апреля 2021 г.

В окончательной редакции 14 апреля 2021 г.

Принято к публикации 14 апреля 2021 г.

Описаны метод изготовления и результаты исследований линзового корректора, преобразующего сферический расходящийся фронт в плоский и предназначенного для изучения плоских поверхностей в составе интерферометра с дифракционной волной сравнения. Особенностью корректора является использование асферической выпуклой поверхности с максимальным отклонением от ближайшей сферы $\sim 200 \mu \mathrm{m}$. Приведены первые экспериментальные результаты, указывающие на перспективы применения ионно-пучковой обработки для улучшения качества волнового фронта. После процедуры ионно-пучковой обработки аберрации по всей апертуре корректора уменьшились более чем в 4 раза и составили по параметру перепада высот $\mathrm{PV}=207 \mathrm{~nm}(\sim \lambda / 3)$ и среднеквадратичного отклонения $(\mathrm{CKO})=19.2 \mathrm{~nm}(\sim \lambda / 33)$. На площади диаметром 80\% аберрации упали до нанометрового уровня: $\mathrm{PV}=65 \mathrm{~nm}(\sim \lambda / 10)$ и СКО $=8.3 \mathrm{~nm}(\sim \lambda / 76)$.

Ключевые слова: линзовый корректор, интерферометрия, асферическая линза, ионно-пучковое травление.

DOI: 10.21883/JTF.2021.10.51374.108-21

\section{Введение}

Интерферометрия является основным методом измерений формы и аберраций оптических элементов и систем в промышленности и в лабораториях [1]. Интерферометры с дифракционной волной сравнения (ИДВС) используют дифракцию света на малой апертуре для генерации расходящейся сферической волны сравнения [2,3]. Амплитудно-фазовые характеристики такой волны могут быть рассчитаны с высокой точностью, что позволяет отнести данный метод интерферометрии к классу „первопринципных“. Однако на практике прямые измерения этим методом могут быть осуществлены только для вогнутых сферических, эллиптических и тороидальных поверхностей, а также объективов. Для других типов оптических элементов и систем требуются различные преобразования расходящейся сферической волны с тем, чтобы ее волновой фронт был близок к форме исследуемой детали. Например, для изучения плоских поверхностей необходимо преобразовать фронт в плоский, а для выпуклых - в сходящийся сферический фронт. Эта задача решается с помощью оптического элемента, называемого корректором волнового фронта [4].

В настоящее время применяются два основных подхода при формировании корректоров: дифракционный и с использованием одиночных линз и объективов [5-10]. Для рентгенооптических приложений, где требуется нанометровая и даже субнанометровая точность формы оптических поверхностей, требуется корректировка аберраций самого корректора. Дифракционный корректор нельзя исправить ионными пучками. Это означает, что для изучения аберраций сверхвысокоточных оптических элементов можно использовать только линзовые корректоры, например $[9,10]$. Однако отмеченные выше корректоры применялись для изучения вогнутых асферических поверхностей с отклонениями от ближайшей сферы менее $10 \mu \mathrm{m}$, что позволяет их изготовить на традиционных оптических станках методом притира с последующей коррекцией аберраций ионными пучками.

Для преобразования расходящегося волнового фронта в плоский или сходящийся требуется гораздо большее преломление и, как следствие, более глубокие асферики. Как показали расчеты, такие асферики должны иметь отклонения от ближайших сфер в сотни $\mu \mathrm{m}$. Такие поверхности уже не могут быть изготовлены с помощью классического притира и делаются на ультрапрецизионных станках с числовым программным управлением с использованием малоразмерного инструмента.

Целью настоящей работы является изучение параметров асферической линзы, изготовленной указанным методом и возможности ее использования для изучения плоских поверхностей в качестве корректора волнового фронта.

\section{1. Расчет корректора волнового фронта}

Расчет корректора волнового фронта был выполнен для разработанного впервые ИДВС, предназначенного для эксплуатации в условиях реального производства [11,12]. Расчет плоско-выпуклого корректора 


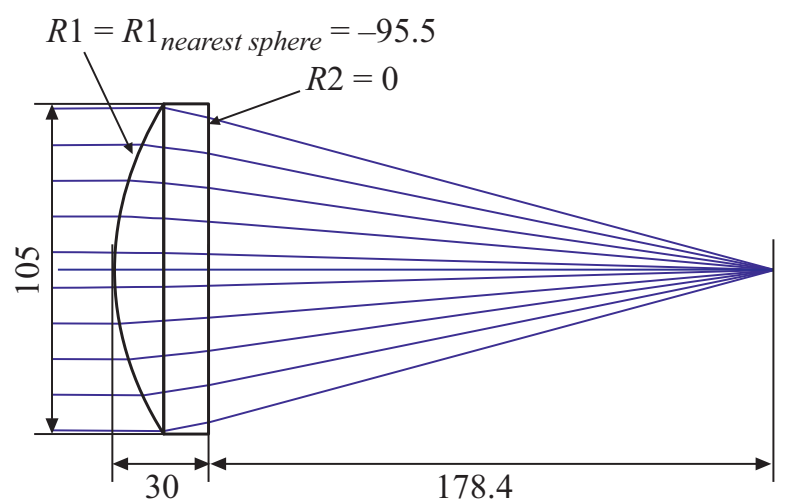

Рис. 1. Схема корректора для ИДВС, преобразующего расходящийся сферический фронт источника сферической волны в плоско-параллельный волновой фронт.

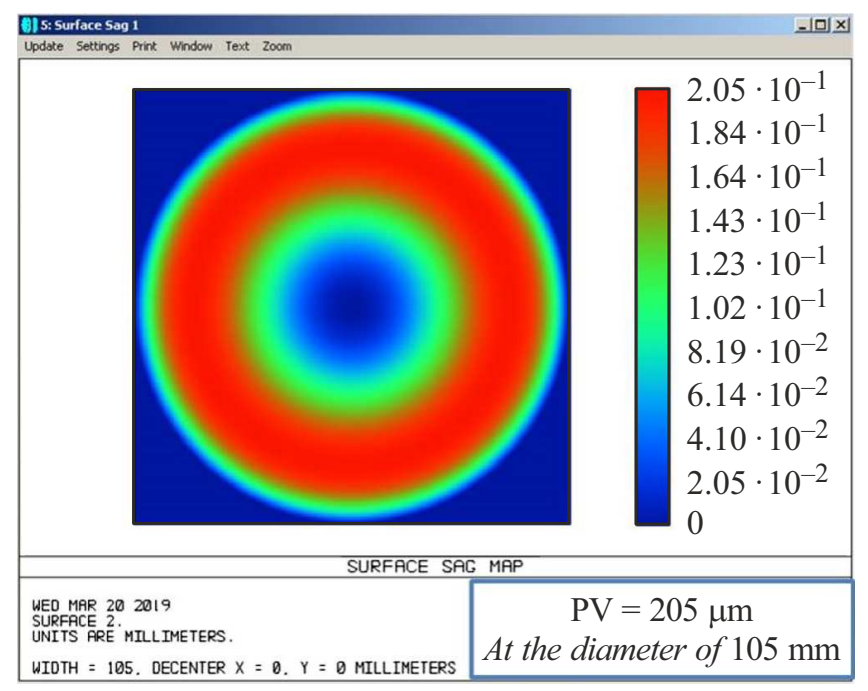

Pис. 2. Карта для асферизации выпуклой поверхности корректора.

(рис. 1) проводился в программе Zemax. Фиксированными входными данными для оптимизации были: материал - плавленый кварц КУ-1; расстояние между источником сферической волны, установленным в фокус корректора, и корректором, равное $178.4 \mathrm{~mm}$; входная апертура $\mathrm{NA}=0.26$; толщина $30 \mathrm{~mm}$ и диаметр $105 \mathrm{~mm}$. Фиксированные геометрические параметры корректора были выбраны из конструктивных особенностей интерферометра с тем, чтобы можно было установить разработанный корректор на интерферометр взамен ранее использованного без серьезной юстировки прибора, материал - в силу его хорошей однородности кварца КУ-1, позволяющей производить ионное травление на большие глубины без развития шероховатости поверхности.

После оптимизации был найден радиус кривизны выпуклой поверхности корректора (радиус ближайшей сферы), равный $-95.5 \mathrm{~mm}$, а также коэффициенты при полиномах, описывающие отклонение $h(r)$ асферической поверхности от ближайшей сферы:

$$
\begin{aligned}
h(r)= & 2.6125 \cdot 10^{-4} \cdot r^{2}-7.320 \cdot 10^{-8} \cdot r^{4} \\
& -5.302 \cdot 10^{-12} \cdot r^{6}-9.011 \cdot 10^{-16} \cdot r^{8},
\end{aligned}
$$

где $r=0-52.5 \mathrm{~mm}$ - радиус рассматриваемой точки на выпуклой поверхности.

Асферическая форма выпуклой поверхности корректора (рис. 2) имеет осесимметричный вид и устраняет сферическую аберрацию. Максимальный перепад высот составил $\mathrm{PV}=205 \mu \mathrm{m}$.

\section{2. Методика и результаты эксперимента}

\section{1. Изготовление и изучение аберраций корректора волнового фронта}

Изготовление асферической линзы-корректора производилось на линейке из асферошлифовального и асферополировального станков известных производителей: Schneider, Optotech и SatisLOH. Контроль формы асферики производился как непосредственно во время изготовления (профилометр), так и при окончательной сдаче детали (интерферометр). Оба прибора имели обратную связь со станками для внесения коррекции в программу обработки деталей после промежуточных замеров. В настоящей работе использовались профилометр Talysurf 1240 английской фирмы TAYLOR HOBSON и интерферометр ZYGO. По данным производителя технология обеспечивает следующую точность изготовления асферических поверхностей: $\mathrm{PV}=0.5 \lambda$ и среднеквадратическим отклонением $(\mathrm{CKO})=0.07 \lambda$, где $\lambda-$ рабочая длина волны интерферометра.

Изучение аберраций волнового фронта проводилось с помощью ИДВС на основе одномодового оптического волокна с субволновой выходной апертурой на стенде горизонтального интерферометра, описанном в [13]. Фотография стенда с обозначениями основных элементов схемы измерений приведена на рис. 3. Сферическая расходящаяся волна выходит из интерферометра 1 и

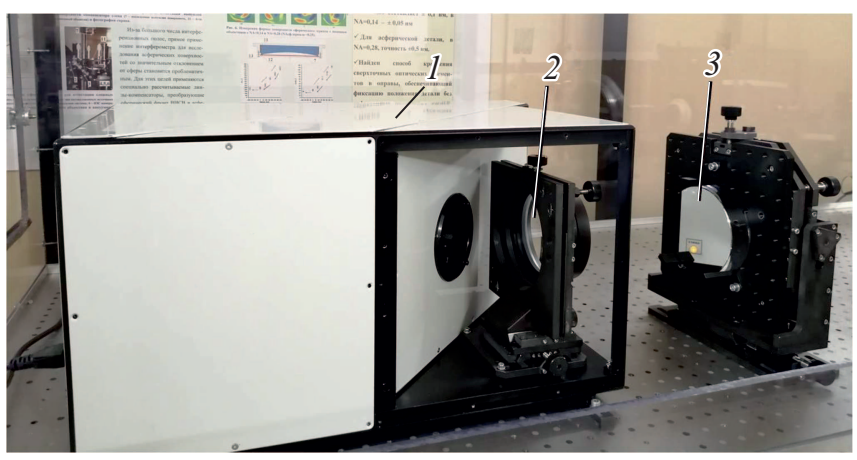

Рис. 3. Схема измерений аберраций корректора волнового фронта: 1 - ИДВС, 2 - изучаемый корректор, 3 - эталонная плоскость. 


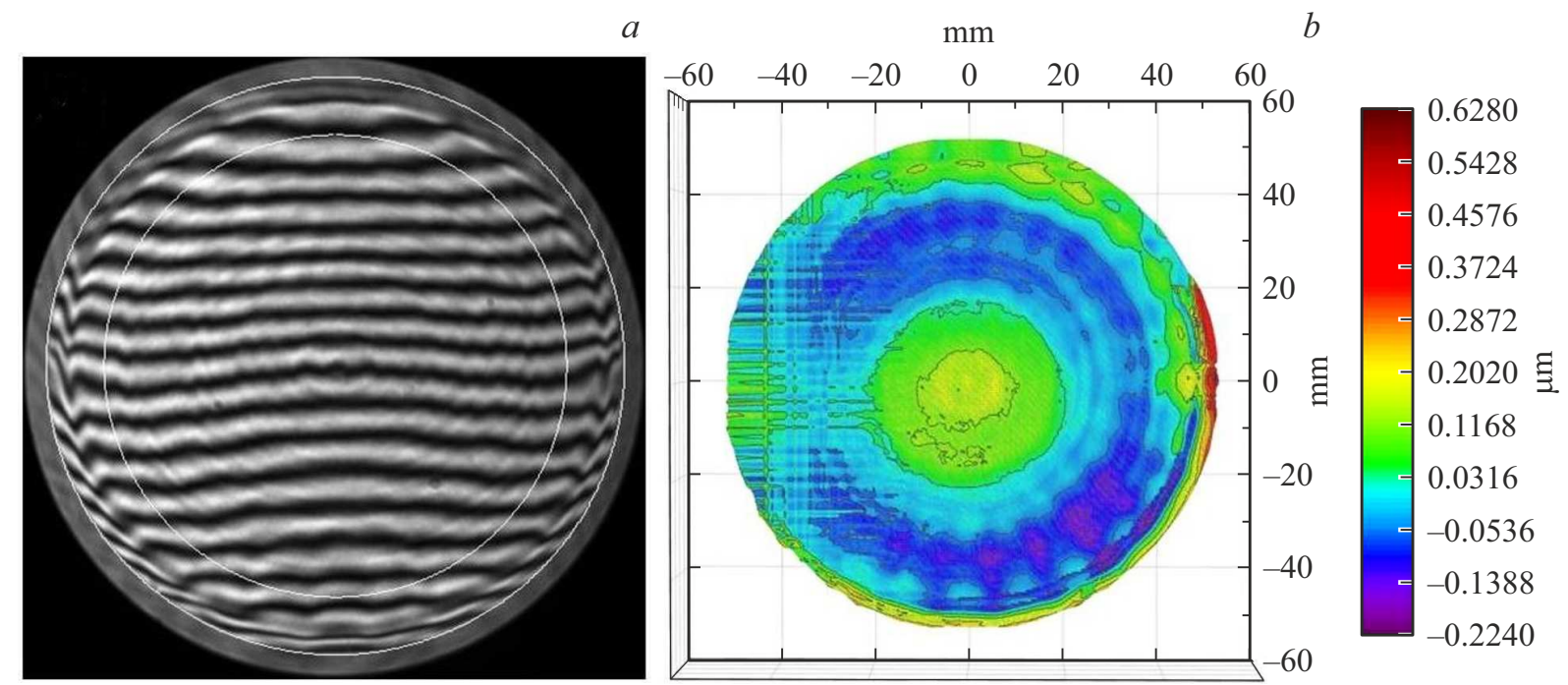

Рис. 4. Интерферограмма (a) и карта аберраций $(b)$ корректора. Белым кружком отмечена область с диаметром 80\%.

падает на корректор волнового фронта 2, на выходе которого формируется плоский фронт. Этот фронт падает на плоское эталонное зеркало 3 и, отражаясь, возвращается обратно в интерферометр по близкому пути. В данном эксперименте использовался предварительно измеренный плоский эталон с СКО $\sim \lambda / 100$. Ошибка эталона в процессе измерений не учитывалась. Также не применялась методика повышения точности измерений, описанная в [10], так как ошибки корректора были существенно больше $\lambda / 100$.

На рис. 4 приведены измеренная интерферограмма и восстановленная по ней карта отклонений волнового фронта от требуемого. Измеренные на 100\% площади аберрации корректора составили СКО $=79.7 \mathrm{~nm}$ $(\sim \lambda / 8)$, перепад высот $\mathrm{PV}=849 \mathrm{~nm} \quad(\sim 1.3 \lambda)$. На апертуре диаметром $80 \%$ аберрации составили: $\mathrm{CKO}=37.9 \mathrm{~nm}(\sim \lambda / 17)$, перепад высот $\mathrm{PV}=304 \mathrm{~nm}$ $(\sim \lambda / 2)$.

Как по виду интерферограммы, так и восстановленной по ней карте аберраций видно, что волновой фронт содержит значительную долю высокочастотных аберраций. Причем они имеют определенную симметрию, что, по нашему мнению, связано с особенностями формообразования поверхностей с использованием малоразмерного инструмента. На деталях, полученных методом притира, например, [14], таких структур и высоких частот не наблюдается.

Так же можно отметить, что параметры корректора не удовлетворяют критерию Марешаля на допустимые аберрации для оптики дифракционного качества $\mathrm{CKO} \leq \lambda / 14$ даже для видимого диапазона [15].

\section{2. Улучшение поверхности корректора методом ионно-пучкового травления}

Для исправления аберраций корректора волнового фронта использовался метод ионно-пучкового травле- ния. Эксперименты проводились на установке и по методикам, описанным в [16]. Единственным отличием является то, что при расчете траектории движения ионного пучка по детали использовался усовершенствованный алгоритм, позволяющий при том же диаметре ионного пучка в 2 раза повысить пространственные частоты неоднородностей, которые могут обрабатываться в процессе ионного травления [17].

Для ускорения процесса коррекции из суммарной аберрации выделялась осесимметричная часть ошибки, которая исправлялась с использованием сильноточного широкоапертурного пучка [16]. Оставшиеся локальные ошибки уже корректировались малоразмерным ионным пучком. Уменьшение аберраций производилось методом травления выпуклой поверхности. При пересчете измеренных аберраций в карту травления поверхности учитывался двойной проход света через исследуемую деталь. Кроме того, в отличие от тестирования зеркальной оптики, также учитывался и показатель преломления материала корректора. Поэтому измеренная аберрация $\Psi$ связана с ошибкой формы соотношением

$$
\Delta \Psi=2(n-1) \Delta x
$$

где $n-$ показатель преломления материала корректора, $\Delta x$ - ошибка профиля поверхности.

На рис. 5 приведены интерферограмма и карта аберраций волнового фронта после одной процедуры коррекции осесимметричной и локальных ошибок. Как видно из рисунка, как и в первом случае, в карте аберраций доминируют высокочастотные ошибки. Тем не менее величина аберрации упала более чем в 4 раза и составила на площади $100 \%$ : $\mathrm{PV}=207 \mathrm{~nm}$ $(\sim \lambda / 3)$ и $\mathrm{CKO}=19.2 \mathrm{~nm}(\sim \lambda / 33)$. На площади диаметром $80 \%$ они упали до нанометрового уровня: $\mathrm{PV}=65 \mathrm{~nm}(\sim \lambda / 10)$ и СКО $=8.3 \mathrm{~nm}(\sim \lambda / 76)$. 


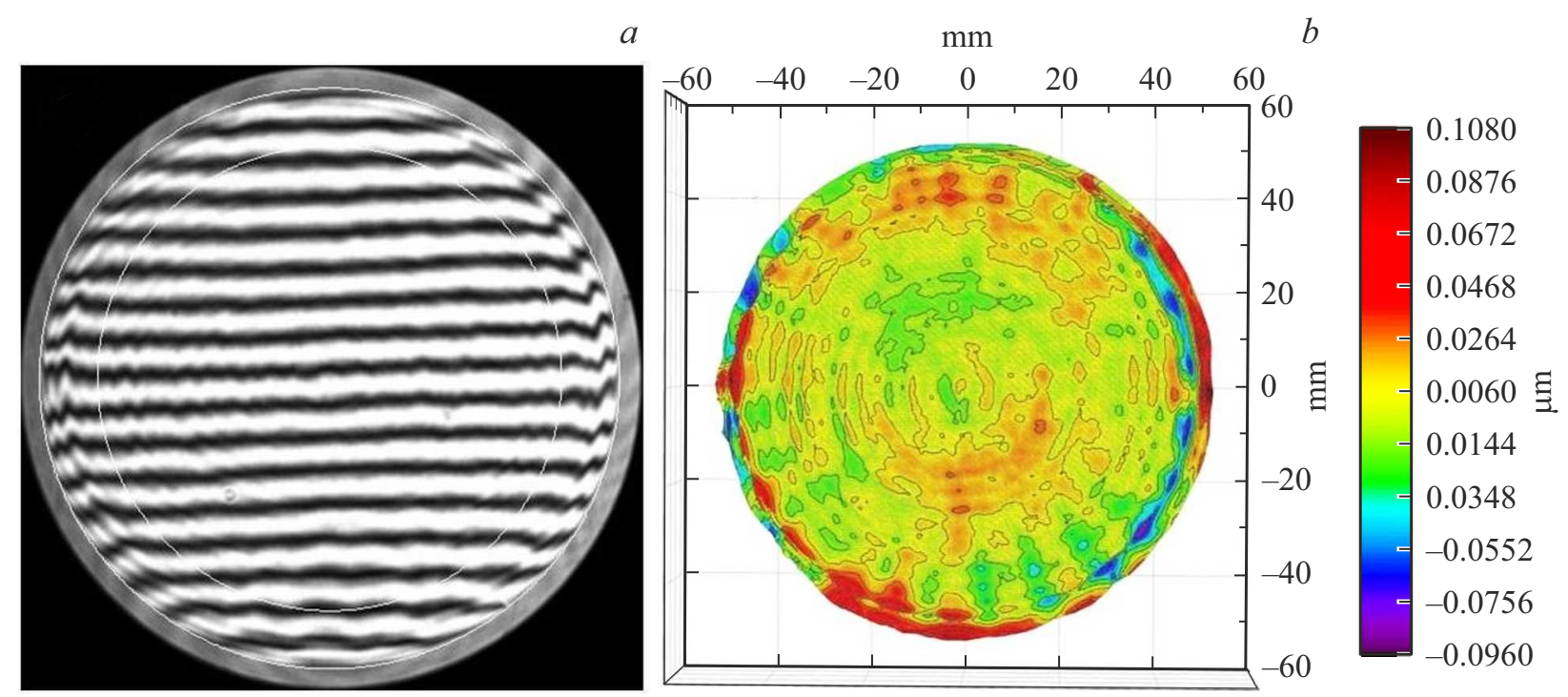

Рис. 5. Интерферограмма $(a)$ и карта аберраций $(b)$ корректора после ионной полировки. Белым кружком отмечена область с диаметром $80 \%$.

\section{3. Обсуждение результатов и основные выводы}

В работе проведено исследование аберраций корректора волнового фронта для преобразования сферической расходящейся волны в плоский фронт, представляющего собой плоско-выпуклую линзу с асферическим профилем выпуклой поверхности и изготовленного методом точения малоразмерным инструментом. Исследование показало наличие значительных высокочастотных аберраций, а основные параметры аберраций составили следующие величины. На 100\% площади корректора СКО $=79.7 \mathrm{~nm}(\sim \lambda / 8)$, перепад высот $\mathrm{PV}=849 \mathrm{~nm}(\sim 1.3 \lambda)$. На апертуре диаметром $80 \%$ аберрации составили: СКО $=37.9 \mathrm{~nm}(\sim \lambda / 17)$, перепад высот $\mathrm{PV}=304 \mathrm{~nm}(\sim \lambda / 2)$. Полученные аберрации лишь частично удовлетворяют требованиям к оптике дифракционного качества для видимого диапазона длин волн в области диаметром $80 \%$.

Изучена принципиальная возможность использования ионно-пучкового травления для уменьшения аберраций корректоров с такой „глубокой“ асферикой. Подтверждена эффективность такого подхода. Показано, что после процедуры ионно-пучковой обработки аберрации по всей апертуре корректора уменьшились более чем в 4 раза и составили по параметру перепада высот $\mathrm{PV}=207 \mathrm{~nm}(\sim \lambda / 3)$ и $\mathrm{CKO}=19.2 \mathrm{~nm}(\sim \lambda / 33)$. На площади диаметром $80 \%$ они упали до нанометрового уровня: $\mathrm{PV}=65 \mathrm{~nm}(\sim \lambda / 10)$ и СКО $=8.3 \mathrm{~nm}(\sim \lambda / 76)$. Этот результат уже позволяет использовать корректор для изучения плоских поверхностей и аберраций телескопов для видимого и даже УФ диапазонов длин волн, а на области диаметром $80 \%$ - даже для вакуумного ультрафиолета.
Для удовлетворения требований к оптике экстремального ультрафиолетового диапазона планируется дальнейшее улучшение качества волнового фронта корректора за счет повторных процедур коррекции локальных ошибок ионным пучком.

\section{Благодарности}

Работа выполнена в рамках государственного задания 0030-2021-0022 при поддержке грантов РФФИ №№ 20-02-00364 А ,20-32-90169 и 19-02-00081.

\section{Конфликт интересов}

Авторы заявляют, что у них нет конфликта интересов.

\section{Список литературы}

[1] М.А. Окатов, Э.А. Антонов, А. Байгожин, М.И. Бакаев, И.В. Белова, И.Я. Бубис, В.А. Вейденбах, Н.М. Воронцова, С.В. Данилов, Н.Ю. Дудкина, И.И. Духопел, С.М. Кузнецов, 3.А. Куклева, Г.В. Листратова, Б.И. Лодыгин, Ю.К. Лысяный, С.В. Любарский, А.В. Михайлов, В.Я. Назарова, Е.И. Понфиленок, Б.И. Петров, Г.Т. Петровский, В.П. Повещенко, Г.Д. Придатко, С.М. Прохорчик, В.Н. Савушкин, Р.С. Соколова, Н.В. Суйковская, Л.В. Тарновская, И.Д. Торбин, Л.А. Черезова, Б.А. Чунин, А.В. Шатилов, Э.И. Шепурев, 3.В. Широкшина, В.Х. Ягмуров. Справочник технолога-оптика, под ред. М.А. Окатова. (Политехника, СПб, 2004), с. 679.

[2] G.E. Sommargren. Laser Focus World, 8, 61 (1996).

[3] K. Otaki, K. Ota, I. Nishiyama, T. Yamamoto, Y. Fukuda, S. Okazaki. J. Vac. Sci. Technol. B, 20 (6), 2449 (2002). https://doi.org/10.1116/1.1526605

[4] D. Malacara, ed. Optical shop testing. (2 ed.) (John Wiley\&Sons, Inc., N Y., 1992) ISBN 0-471-52232-5, 
[5] U. Dinger, F. Eisert, H. Lasser, M. Mayer, A. Seifert, G. Seitz, S. Stacklies, F.-J. Stickel, M. Weiser. Proc. SPIE, 4146, 35 (2000). DOI: $10.1117 / 12.406674$

[6] J.M. Sasian. Opt. Eng., 27 (12), $1051 \quad$ (1988). DOI: $10.1117 / 12.7978676$

[7] J.H. Burge. Proc. SPIE, 2576, 258 (1995).

[8] C. Zhao, J.H. Burge., Proc. SPIE, 6723, 67230L (2007). DOI: $10.1117 / 12.782920$

[9] Н.Б. Вознесенский, Е.В. Гаврилов, А.П. Жевлаков, В.К. Кирилловский, П.В. Орлов. ЖТФ, 77 (2), 126 (2007). [N.B. Voznesensky, E.V. Gavrilov, A.P. Zhevlakov, V.K. Kirillovskie, P.V. Orlov. Tech. Phys., 52 (2), 271 (2007). DOI: 10.1134/S106378420702020X]

[10] N.I. Chkhalo, I.V. Malyshev, A.E. Pestov, V.N. Polkovnikov, N.N. Salashchenko, M.N. Toropov, A.A. Soloviev. Appl. Opt., 55 (3), 619 (2016). DOI: 10.1364/AO.55.000619

[11] А.А. Ахсахалян, Д.А. Гаврилин, И.В. Малышев, Н.Н. Салащенко, М.Н. Торопов, Б.А. Уласевич, Н.Н. Цыбин, Н.И. Чхало. ЖТФ, 89 (11), 1789 (2019). DOI: 10/21883/jtf.2019.11.48346.115-19 [A.A. Akhsakhalyan, D.A. Gavrilin, I.V. Malyshev, N.N. Salashchenko, M.N. Toropov, B.A. Ulasevich, N.N. Tsybin, N.I. Chkhalo. Tech. Phys., 64 (11), 1698 (2019).]

[12] М.Н. Торопов, Н.И. Чхало, Н.Н. Салащенко, И.В. Малышев, Б.А. Уласевич, Д.А. Гаврилин, А.А. Ахсахалян. „ИНТЕРФЕРОМЕТР““. Заявка 201918818. Приоритет 18.06.20193. Зарегистрировано в Госреестре 19.02.2020. № 271486 .

[13] N.I. Chkhalo, I.V. Malyshev, A.E. Pestov, V.N. Polkovnikov, N.N. Salashchenko, M.N. Toropov. Physics-Uspekhi, 63 (1), 67 (2020). DOI: 10.3367/UFNe.2019.05.038601

[14] М.Н. Торопов, А.А. Ахсахалян, М.В. Зорина, Н.Н. Салащенко, Н.И. Чхало, Ю.М. Токунов. ЖТФ, 90 (11), 1958 (2020). DOI: 10.21883/JTF.2020.11.49990.127-20 [M.N. Toropov, A.A. Akhsakhalyan, M.V. Zorina, N.N. Salashchenko, N.I. Chkhalo, Yu. M. Tokunov. Tech. Phys., 65 (11), 1873 (2020).]

[15] М. Борн, Э. Вольф. Основы оптики (Наука, М., 1973)

[16] N.I. Chkhalo, I.A. Kaskov, I.V. Malyshev, M.S. Mikhaylenko, A.E. Pestov, V.N. Polkovnikov, N.N. Salashchenko, M.N. Toropov, I.G. Zabrodin. Precision Engineer., 48, 338 (2017).

DOI: http://dx.doi.org/10.1016/j.precisioneng.2017.01.004

[17] A. Chernyshev, N. Chkhalo, I. Malyshev, M. Mikhailenko, A. Pestov, R. Pleshkov, R. Smertin, M. Svechnikov, M. Toropov. Precision Engineer., 69, 29 (2021). https://doi.org/10.1016/j.precisioneng.2021.01.006 